\title{
Custos de Conformidade à Tributação: Uma análise da percepção de gestores e colaboradores em uma empresa estadual de saneamento
}

\author{
Glavany Lima Maia \\ Mestrado em Controladoria pela Universidade Federal do Ceará - UFC \\ Analista Judiciário do Tribunal Regional Eleitoral do Ceará \\ Rua Vicente de Castro Filho, 1460, Ap 1201. Luciano Cavalcante. Fortaleza/CE \\ E-mail: glavany@uol.com.br
}

Maria Naiula Monteiro Pessoa Doutorado em Engenharia de Produção pela Universidade Federal de Santa Catarina UFSC

Professora da Universidade Federal do Ceará - UFC Av. da Universidade, 2486. Benfica. Fortaleza/CE E-mail: naiula@ufc.br

Sandra Maria dos Santos

Pós-Doutorado pela Universidade Federal de Pernambuco - UFPE

Professora da Universidade Federal do Ceará - UFC Av. da Universidade, 2486. Benfica. Fortaleza/CE

E-mail:smsantos@ufc.br

Augusto César Cabral Doutorado em Administração pela Universidade Federal de Minas Gerais - UFMG Professora da Universidade Federal do Ceará - UFC Av. da Universidade, 2486. Benfica. Fortaleza/CE E-mail: cabral@ufc.br

\section{RESUMO}

Os custos de conformidade à tributação correspondem aos dispêndios incorridos pelos contribuintes no cumprimento das determinações legais tributárias. Incluem os custos de tempo e recursos consumidos em atividades como cálculo e retenção de impostos e contribuições, preenchimento de declarações, atendimento a fiscalizações, e os gastos em planejamento tributário, pesquisas e treinamentos, entre outros. $\mathrm{O}$ objetivo do estudo é analisar a percepção de gestores e colaboradores de uma empresa estadual de saneamento a respeito dos custos de conformidade à tributação. A pesquisa classifica-se como de natureza qualitativa, com delineamento exploratóriodescritivo. Quanto aos meios, trata-se de um estudo de caso único. Neste estudo, foram utilizadas como fontes de evidências: a pesquisa bibliográfica e documental, o questionário estruturado e roteiro de entrevista semi-estruturada. $\mathrm{O}$ tratamento desses instrumentos envolveu o uso de métodos quantitativos (análise exploratória dos dados) e qualitativos (análise de conteúdo). Os resultados mostraram que há uma percepção intuitiva da existência dos custos de conformidade à tributação, e de seu crescimento principalmente em decorrência da complexidade e instabilidade das normas fiscais, mas não há apuração ou controle desses custos na empresa pesquisada.

Palavras-chave: Custo de conformidade fiscal. Impostos. Gestão de custos. 


\title{
Compliance Costs of Taxation: an analysis of perception of managers and collaborators of a state company of sanitation
}

\begin{abstract}
The compliance costs of taxation correspond to the costs incurred by taxpayers in meeting the legal tax requirements. They include the costs of time and resources consumed in activities, such as the calculation and retention of taxes and contributions, filing the returns, dealing with the tax authority audit, and expenses on tax planning, research and training, among others. This work aims to assess the perception of managers and collaborators of a state company of sanitation with respect to the compliance costs of taxation. This study uses the bibliographical and documental research and single case study, with structured questionnaires and semi-structured interviews. The results obtained show that since there is no investigation or control of compliance costs of taxation in the evaluated company, there is an intuitive perception of not only the existence of theses costs but also their growth, mainly due to the complexity and instability of fiscal rules.
\end{abstract}

Keywords: Tax compliance cost. Taxes. Management of Costs.

\section{INTRODUÇÃO}

Muito se discute a respeito do excessivo ônus tributário imposto às empresas brasileiras. Os meios de comunicação revelam que a carga tributária brasileira está em constante ascensão e figura entre as maiores do mundo. Porém, os percentuais da carga tributária divulgados só levam em consideração uma parte dos custos totais relacionados à tributação.

Quando se faz referência à carga tributária, fala-se apenas do montante de tributos (impostos, taxas e contribuições) arrecadados. Entretanto, além do peso da arrecadação sobre o Produto Interno Bruto (PIB), há que se considerar também os gastos com o gerenciamento e controle das atividades tributárias, relacionados ao Sistema Tributário.

Para Bertolucci (2003), trata-se de questões distintas, tendo em vista que qualquer país pode ter uma carga tributária muito alta e um sistema tributário racional, como pode ter uma carga tributária baixa e um sistema tributário caótico. No Brasil, 
existe a combinação de carga excessiva com sistema tributário de má qualidade.

Os sacrifícios de recursos necessários somente para atender às disposições legais tributárias são denominados, na literatura internacional, tax compliance costs ou compliance costs of taxation. Os custos de conformidade à tributação, normalmente, incluem os custos do trabalho ou tempo consumido na conclusão de atividades tributárias, como cálculo de impostos, preenchimento de declarações, retenção de tributos, conservação de documentos, atendimento a fiscalizações, bem como os gastos em pesquisas e planejamento tributário, treinamentos, contratação de consultorias; incorridos para compreender e cumprir todas as formalidades que são exigidas pela legislação tributária (Evans;Tran-Nam, 2001; Pope, 2000).

Evans (2003) revela que até meados do século XX muito pouco havia sido feito em pesquisas sobre os custos de conformidade à tributação. Entretanto, o cenário de negligência inicial da pesquisa tem mudado no contexto internacional, pois tem havido um ininterrupto crescimento do interesse, particularmente entre países da Organização para a Cooperação e Desenvolvimento Econômico (OECD), sobre os custos de conformidade à tributação, tanto por pesquisadores acadêmicos quanto pelos governos (Evans et al., 2000).

No Brasil, embora a carga tributária seja um tema contemporâneo de discussão no meio acadêmico e empresarial, poucos autores brasileiros se debruçaram sobre a questão da conformidade tributária, que, certamente, poderia levar à economia de recursos nas empresas e no país.

O presente estudo tem como objetivo analisar a percepção dos gestores e colaboradores a respeito dos custos de conformidade à tributação em uma empresa estadual de saneamento. Quanto aos procedimentos metodológicos, a pesquisa é de natureza qualitativa, exploratória e descritiva. Quanto aos meios ou ao escopo, a pesquisa classifica-se como um estudo de caso único. Neste estudo, foram utilizadas como fontes de evidências, a pesquisa bibliográfica e documental, o questionário estruturado e roteiro de entrevista semi-estruturada. $O$ tratamento desses instrumentos de coleta envolveu o uso de métodos quantitativos (análise exploratória dos dados) e qualitativos (análise de conteúdo). O estudo de caso foi desenvolvido na Companhia de 
Água e Esgoto do Ceará (Cagece).

\section{CUSTOS DE CONFORMIDADE À TRIBUTAÇÃO}

Estudos iniciais sobre custos da tributação trazem diversas abordagens sobre os custos gerados pelos tributos. Bertolucci (2003) resume as ideias de Cedric Sandford, professor emérito de Economia Política da Universidade de Bath, no Reino Unido, e Chefe do Centro de Estudos Fiscais daquela universidade, para quem os custos de tributos podem ser classificados em três categorias:

a) Os mais óbvios são os próprios impostos que representam sacrifícios da renda em troca das despesas que o poder público faz com essa arrecadação.

b) Os custos de distorção, ou seja, as mudanças do comportamento na economia em virtude da existência de tributos, alterando preços de produtos e dos fatores de produção.

c) Os custos dos recursos empregados para operar o sistema tributário, ou um tributo individual, e que poderiam ser poupados se os tributos não existissem. Denominam-se custos operacionais tributários (Bertolucci, 2003, p.20-21).

Essa última categoria tem sido usada para representar a soma dos custos administrativos - custos do Poder Público relacionados à tributação - e dos custos de conformidade - custos impostos aos contribuintes como resultado do cumprimento de suas obrigações tributárias.

O Código Tributário Nacional (Lei n.. 5.172, de 25/10/1966), trata, em seu artigo 113, §2.․ das obrigações acessórias - obrigações que decorrem da legislação tributária e têm por objeto as prestações, positivas ou negativas, nela previstas no interesse da arrecadação ou da fiscalização dos tributos. Todavia, os custos de conformidade têm uma abrangência maior que os custos das obrigações acessórias, por incluírem, normalmente, os gastos com treinamento, planejamento fiscal e contratação de consultoria especializada para auxiliar na realização das atividades tributárias e outras despesas incorridas para cumprir todas as formalidades que são exigidas pela 
legislação tributária.

Evans et al (2000) afirmam que os custos de conformidade foram tratados por muito tempo como "custos ocultos" da tributação e que um consenso a respeito do significado preciso do termo compliance costs of taxation somente começou a emergir na literatura há aproximadamente 25 anos.

Bertolucci (2003) destaca que o termo é ambíguo tanto em inglês como em português, mas deve ser compreendido como o custo de conformar sua atividade às normas tributárias, assumindo a forma estabelecida pelo Poder Público.

A literatura sobre custos de conformidade na tributação distingue ainda qualificações e subdivisões que precisam ser levadas em conta em qualquer definição de custos de conformidade.

Os custos de conformidade à tributação compreendem custos monetários e não monetários. Conforme Warburton e Hendy (2006), custos monetários são aqueles que estão incorporados ao desempenho financeiro dos negócios e estão provavelmente refletidos no lucro da empresa. Eles incluem o custo de: adquirir o conhecimento necessário dos aspectos relevantes do sistema tributário; compilação de arquivos; aquisição e manutenção de sistemas contábeis e fiscais; preenchimento de formulários fiscais; avaliação da eficácia tributária de transações alternativas ou métodos alternativos no cumprimento das exigências legais; e reter e recolher impostos cobrados dos empregados e dos negócios.

Pope (2000) aponta que, para as empresas, os custos monetários incluem gastos com honorários profissionais de contadores, advogados e outros consultores; e o custo de tempo do pessoal interno na manutenção de informações fiscais ao longo do ano; preenchimento de declarações fiscais próprias ou na preparação de informações para profissionais de consultoria; relações com as autoridades fiscais.

Por sua vez, os custos de conformidade não monetários são custos intangíveis provocados pela operação do sistema tributário, que, embora sejam difíceis de quantificar, provavelmente também estão refletidos nos resultados das empresas.

[...] há custos de conformidade que não são prontamente quantificados em termos monetários. Em particular, é preciso considerar também os custos psicológicos da 
obediência às obrigações fiscais. Os custos psicológicos neste contexto referem-se à ansiedade e frustração no aprendizado e no cumprimento as mudanças tributárias. (Evans; Tran-Nam, 2001, p.7-8) [tradução nossa].

Pope (2000) afirma que os custos não-monetários incluem os custos psicológicos de estresse e ansiedade provenientes da obediência a um tributo específico ou a uma atividade relacionada a tributo, tal como auditoria de uma autoridade fiscal. Todavia, Pope (2000, p.3) ressalta que "a existência de tais custos não-econômicos é reconhecida, embora normalmente ignorada" [tradução nossa].

De fato, Evans e Tran-Nam (2001) relatam que, infelizmente, nenhum estudo conseguiu ainda quantificar com êxito estes custos psicológicos, embora esteja ocorrendo pesquisa nesta área, com Robin $\mathrm{H}$. Woellner e outros.

Das-Gupta (2003) menciona que os custos de conformidade incluem elementos obrigatórios e voluntários. Esta distinção entre custos de conformidade voluntários (tax planning costs) e involuntários ou inevitáveis (computational costs) foi feita introdutoriamente na literatura por Kenneth Stanton Johnston, em 1963, em estudo apresentado a Universidade de Ohio.

Custos obrigatórios são aqueles que os contribuintes precisam incorrer para atender às obrigações tributárias, tais como conservação de livros fiscais; preenchimento de certos tipos de relatórios; autorizações e permissões onde exigidas pela lei, ou estar apto a comprovar deduções pretendidas. Custos voluntários são principalmente associados com planejamento tributário ou elisão fiscal empreendida pelos contribuintes para reduzir o ônus fiscal, tendo em vista que tais custos são presumivelmente menores que as consequentes reduções nas suas obrigações tributárias (Evans et al, 2000).

Contudo, Evans e Tran-Nam (2001, p.7) destacam que "ambos os tipos de despesas são legitimamente incorridos por contribuintes no cumprimento das exigências legislativas" [tradução nossa].

Sandford, Godwin e Hardwick (1989) distinguem ainda os custos de conformidade nas categorias de custos transitórios ou recorrentes. O termo custos transitórios é comumente usado para referir-se a custos de início (commencement or 
start-up costs) e custos temporários (temporary costs). Os custos recorrentes ou regulares (recurrent or regular costs) são os que se mantêm, depois da fase inicial de aprendizado. Uma vez que a legislação tributária tende a mudar continuamente, os custos de início e os custos recorrentes existem simultaneamente no sistema tributário como um todo.

Os custos de conformidade transitórios podem, portanto, incluir: os custos de aprendizado e suas implicações (tempo e custos de treinamento de pessoal); análise das mudanças e eventuais pagamentos a consultores tributários externos; aquisição de novos softwares fiscais ou sua atualização para adaptar-se às mudanças e outras modificações necessárias de sistemas contábeis e gerenciais. Os custos recorrentes compreendem os custos que permanecem depois que as rotinas são incorporadas à cultura da entidade e se atingiu o nível de eficiência adequado.

\subsection{Custos de Conformidade à Tributação no Brasil}

Bertolucci (2003) expõe que não encontrou bibliografia brasileira voltada especificamente aos custos de conformidade e que os autores brasileiros demonstram preocupação com relação ao tema, mas sempre dentro do âmbito maior que tem sido a reforma tributária. Ele destaca que, no Brasil, as partes envolvidas - contribuintes, administração tributária e o meio acadêmico - ainda não se debruçaram sobre a questão do custo de conformidade que, certamente, poderá levar à economia de grandes recursos pelo país.

Para Bertolucci (2003), um aspecto que influencia os custos de conformidade no Brasil é o próprio pacto federativo e a forma como a Constituição Federal define a competência tributária.

No Brasil, cada uma das pessoas jurídicas de direito público, vale dizer, a União, os Estados, o Distrito Federal e os Municípios têm sua competência tributária, e, portanto, competência legislativa, atribuída constitucionalmente pelos artigos 153 a 156: "[...] a Constituição Federal delimita, com razoável precisão, a matéria fática de que se pode valer o legislador na instituição de tributos" (Machado, 2005, p. 273).

Bertolucci (2003) entende que a descentralização da legislação tributária 


\section{Custos de Conformidade à Tributação: Uma análise da percepção de gestores e colaboradores emuma \\ empresa estadual de saneamento}

Glavany Lima Maia, Maria Naiula Monteiro Pessoa, Sandra Maria dos Santos, Augusto César Cabral

representa um alto custo para os contribuintes e que se os Constituintes tivessem determinado que os impostos fossem de competência de vários entes, mas impondo uma legislação federal e homogênea, as empresas não seriam tão oneradas. $O$ autor (2003, p.118) destaca que, da forma atual, "os impostos dos Estados terão a legislação multiplicada por 27 e, no limite, as leis dos Municípios serão cerca de 5.000, que é o número aproximado de municípios no país".

Rezende (2004, p.8), em artigo intitulado "Pandemônio Tributário", ressalta que

se a ninguém é lícito escusar-se do cumprimento da lei alegando seu desconhecimento, torna-se imperioso que o contribuinte leia e entenda a legislação tributária que possa afetá-lo; e a expressão 'legislação tributária', nos termos do art. 96 do Código Tributário Nacional, compreende as leis, os tratados e as convenções internacionais, as medidas provisórias, os decretos e as normas complementares (abrangendo estas últimas os atos normativos tais como portarias, resoluções, instruções normativas e outros atos menores).

Outro aspecto que influencia os custos de conformidade no Brasil é a instabilidade das normas tributárias brasileiras e a complexidade gerada pelo volume e pelas constantes mudanças na legislação.

Em levantamento realizado em 2006 pelo Instituto Brasileiro de Planejamento Tributário (IBPT, 2006b) para apurar a quantidade de normas editadas nos 18 anos de vigência da Constituição Federal de 1988, verificou-se um total de 229.616 regras tributárias editadas nos três níveis de governo. Em relação à complexidade, o estudo destaca que, em média, cada norma tributária editada tem 11,23 artigos, cada artigo tem 2,33 parágrafos, 7,45 incisos e 0,98 alíneas. Foram editados nesse período 2.578.588 artigos, 6.008.111 parágrafos, 19.210.484 incisos e

2.527.017 alíneas e, até a data do referido estudo, estavam em vigor 181.275 artigos, 422.370 parágrafos, 1.350 .497 incisos e 177.649 alíneas.

Assim, custos de conformidade podem ser gerados em decorrência da instabilidade da legislação tributária, somada à complexidade do texto legal, que 
impõem às empresas dispêndios de recursos em atividades como pesquisas e planejamento tributário, treinamentos, contratação de consultorias, além das tarefas de conformidade fiscal, bem como questionamentos no contencioso administrativo e judicial.

\section{CONTEXTUALIZANDO O SETOR DE SANEAMENTO}

A discussão sobre a universalização dos serviços de água e esgoto vem ganhando relevância, paralelamente, ao reconhecimento da importância que 0 saneamento possui na qualidade de vida do ser humano e em seu meio ambiente. Essa preocupação com o saneamento e suas relações com a saúde da população remonta às mais antigas civilizações, onde egípcios, gregos e romanos já cuidavam de suas águas e dejetos.

No Brasil, até meados do século passado, eram proeminentes as deficiências quanto à quantidade e à qualidade no abastecimento de água. Foi entre os anos 1970 e 1980 que se expandiu notavelmente a oferta de serviços de saneamento básico, como resultado dos mecanismos institucionais e financeiros postos em marcha pelo Plano Nacional de Saneamento (PLANASA), em que se constituíram as companhias estaduais de saneamento, as quais, até hoje, controlam a maior parte das operações no setor (Arretche, 1999).

Apesar dos grandes avanços verificados nos índices de abastecimento de água e, mais modestamente, na coleta e tratamento de esgotos, há ainda um déficit importante a superar para a universalização desejada. Contudo, segundo a Associação das Empresas de Saneamento Básico Estaduais (AESBE, 2006), nos últimos anos, no sentido contrário das necessidades do setor, não só os investimentos fiscais em saneamento vêm caindo, como vem subindo significativamente a tributação imposta aos prestadores de serviços de saneamento básico.

\subsection{A Companhia de Água e Esgoto do Ceará e seus aspectos tributários}

A Companhia de Água e Esgoto do Ceará (Cagece) é uma sociedade de 
economia mista, criada pela Lei estadual n. 9 9.499, de 20 de julho de 1971, e tem por objetivo o tratamento e a distribuição de água tratada, a coleta e o tratamento de esgotos sanitários no Estado do Ceará. O Governo do Estado do Ceará, como acionista controlador, detém $84,07 \%$ do capital votante da companhia.

Nos últimos anos, a Cagece tem buscado alcançar um patamar de destaque no setor de saneamento brasileiro, através de um processo crescente de modernização tecnológica, administrativa e profissionalização de sua gestão (Cagece, 2006).

Atualmente, a empresa está presente em cerca de 243 localidades do Estado, de 149 municípios. A companhia encerrou o ano de 2005 garantindo água tratada a 5,9 milhões de cearenses e beneficiando aproximadamente 2,1 milhões de pessoas com os serviços de esgotamento sanitário, presente em $81 \%$ dos municípios cearenses com serviços de água e em $28 \%$ com o esgotamento sanitário (Cagece, 2006).

Aspectos tributários da Cagece contribuíram para a definição da empresa a ser pesquisada, tendo em vista a facilidade de identificação de custos de conformidade à tributação. Na esfera federal, por exemplo, são perceptíveis os custos de conformidade gerados pela modalidade de apuração e cálculo do Imposto sobre a Renda a que a companhia está obrigada - apuração pelo Lucro Real, em que a base de cálculo do imposto é apurada segundo os registros contábeis e fiscais efetuados, de acordo com as leis comerciais e fiscais. A incidência das Contribuições ao Programa de Integração Social (PIS) e para o Financiamento da Seguridade Social (COFINS) na Cagece se sujeita a não-cumulatividade, conforme instituído pelas leis $n .{ }^{\circ} 10.637$, de 2002 , e n.․ 10.833, de 2003, o que exige um maior controle dos créditos legais e pedidos de compensação ao Fisco federal, gerando mais custos de conformidade.

Entre as obrigações acessórias impostas pela legislação federal estão as exigências de manter escrituração contábil completa; conservar em boa guarda e ordem, enquanto não decorrido o prazo decadencial e não prescritas eventuais ações que Ihes sejam pertinentes, todos os livros obrigatórios pela legislação fiscal, bem como os documentos que serviram de base para escrituração comercial e fiscal; e efetuar as retenções e recolhimentos do imposto de renda e das contribuições na fonte, previstos na legislação vigente. 
A empresa se sujeita ainda à entrega de diversas declarações previstas pela legislação fiscal, tais como:

- Declaração de Informações Econômico-fiscais da Pessoa Jurídica (DIPJ), de periodicidade anual;

- Declaração do Imposto de Renda Retido na Fonte (DIRF), de periodicidade anual;

- Declaração de Débitos e Créditos Tributários Federais (DCTF), de periodicidade mensal;

- Demonstrativo de Apuração de Contribuições Sociais (DACON), de periodicidade mensal;

- Pedido Eletrônico de Restituição ou Ressarcimento e da Declaração de Compensação (PERDCOMP).

A Cagece é contribuinte do Imposto sobre as operações relativas à Circulação de Mercadorias e Serviços (ICMS), de competência estadual, previsto no artigo 155, inciso II, da Constituição Federal. Entretanto, a empresa é beneficiada com a redução de $100 \%$ na base de cálculo nas operações de saída de água natural tratada que realiza, o que equivale, em termos quantitativos, a uma isenção fiscal, uma vez que não há tributo a recolher nessas operações. Não obstante, a companhia está obrigada a cumprir as obrigações acessórias impostas aos contribuintes do ICMS, tais como, registrar os valores totais de suas entradas e saídas em sua escrita fiscal e apresentar declarações de informações econômico-financeiras ao Fisco estadual.

Dentre os tributos de competência municipal, definidos no artigo 156, da Carta Magna, destaque-se que o Imposto sobre Serviços (ISS) não incide sobre os serviços prestados por empresas de saneamento, tendo em vista que foram vetados da lista de serviços anexa à Lei Complementar n. 0 116/2003 os itens referentes à prestação de serviços de saneamento ambiental, inclusive purificação, tratamento, esgotamento sanitário e congêneres e de tratamento e purificação de água.

Embora a companhia não seja contribuinte do ISS, está obrigada a efetuar retenções do imposto daqueles a quem ela toma serviço, como contribuinte substituto, 
obrigando-se ainda a prestar informações ao Fisco Municipal mediante apresentação da Declaração Digital de Serviços (DDS), de periodicidade mensal.

A legislação fiscal vigente e aplicável à empresa estudada atribui de modo expresso a responsabilidade pelo recolhimento e retenção de IR, CSLL, PIS, COFINS e ISS de terceiros. Embora objetivando minimizar ou evitar a evasão fiscal e facilitar 0 controle administrativo do Fisco, esta prática gera custos de conformidade para a organização, como, por exemplo, tempo dedicado e pessoal para a realização das tarefas.

Quanto às contribuições previdenciárias, a empresa, além de contribuir sobre sua folha de salários e demais rendimentos das pessoas por ela contratadas, também é obrigada a recolher as contribuições a cargo de seus empregados e dos prestadores de serviço, mediante desconto da remuneração a eles paga, bem como se sujeita ao cumprimento de outras obrigações acessórias previstas na legislação previdenciária.

Outros tributos previstos pela Constituição Federal e pelo Código Tributário, além dos impostos e contribuições já mencionados, embora não estejam diretamente relacionados à atividade da companhia, como o Imposto sobre a Propriedade Predial e Territorial Urbana (IPTU) e Imposto sobre a Propriedade de Veículos Automotores (IPVA), também geram gastos administrativos com seu gerenciamento e controle.

\section{ASPECTOS METODOLÓGICOS}

A presente pesquisa classifica-se como um estudo de natureza qualitativa, com delineamento exploratório-descritivo, uma vez que a bibliografia nacional sobre tributação e sobre reforma tributária é extremamente rica, mas relativamente poucos autores têm dedicado atenção especificamente aos custos de conformidade à tributação.

Quanto aos meios ou ao escopo, a pesquisa classifica-se como um estudo de caso único, desenvolvido na Companhia de Água e Esgoto do Ceará (Cagece). A decisão de elaborar um estudo de caso único foi adotada com lastro nas observações de Yin (2005), de que o estudo de caso único pode representar um projeto típico, a 
partir do qual podem ser extraídas lições sobre as experiências na instituição.

Foram utilizadas várias fontes de evidências: a pesquisa bibliográfica e documental, o questionário estruturado e o roteiro de entrevista semi-estruturada. $\mathrm{O}$ questionário, dividido em quatro blocos, versando sobre aspectos sócio-demográficos dos respondentes; questões gerais sobre o peso da conformidade tributária; custos de conformidade internos e externos; percepções sobre a qualidade da regulamentação tributária e os custos de conformidade. As entrevistas semi-estruturadas foram desenvolvidas a partir de um roteiro construído com perguntas abertas, tendo como base o referencial teórico da pesquisa.

Os questionários foram aplicados junto aos supervisores e colaboradores das áreas de Análises e Controles Contábeis e Gestão de Fluxos e Disponibilidades, subordinadas, respectivamente, à Gerência de Controladoria e à Gerência Financeira, e da área de Planejamento Econômico-financeiro. As entrevistas foram direcionadas para as assessorias técnicas da Presidência, assessoria jurídica e gerentes das áreas de Controladoria, Financeiro e Pessoal da companhia. Foi uma amostra não probabilística selecionada por selecionada por julgamento, considerando o seu conhecimento e envolvimento com as questões tributárias da empresa. Foram contatadas para a pesquisa dezesseis pessoas, sendo que oito responderam ao questionário, seis participaram da entrevista e duas não aceitaram participar do estudo.

O tratamento desses instrumentos envolveu o uso de métodos quantitativos (análise exploratória dos dados) e qualitativos (análise de conteúdo).

\section{ANÁLISE DOS RESULTADOS DA PESQUISA}

Considerando os resultados obtidos com a aplicação dos questionários, inicialmente, observando-se o perfil dos respondentes, verificou-se que todos têm até 05 anos de empresa. Quanto à formação acadêmica, os supervisores pesquisados têm pós-graduação e os demais colaboradores concluíram ou estão concluindo nível superior.

Os pesquisados foram questionados sobre 08 (oito) aspectos do Código 
Glavany Lima Maia, Maria Naiula Monteiro Pessoa, Sandra Maria dos Santos, Augusto César Cabral

Tributário e legislação correlata. Procurando verificar as maiores fontes de complexidade, eles podiam marcar mais de uma alternativa, se aplicável, bem como indicar outras opções. Os aspectos citados como maiores fontes de complexidade pelo maior número de respondentes (06) foram as regras relativas à determinação da base de cálculo e do valor devido e isenções, reduções e deduções do imposto (Tabela 1).

Tabela 1 - Fontes de complexidade da legislação tributária

\begin{tabular}{l|c}
\multicolumn{1}{c|}{ Aspectos } & Freqüência \\
\hline Determinação da base de cálculo e do valor devido & 6 \\
Isenções, reduções e deduções do imposto devido & 6 \\
Tributação na fonte & 3 \\
Imunidades, isenções e não incidências & 2 \\
Compensação e restituição de tributos pagos & 1 \\
Depreciação de bens / Depreciação acelerada incentivada & 1 \\
Outros $^{1}$ & 2 \\
\hline
\end{tabular}

Fonte: Dados da pesquisa

a. Outros: Interpretação das normas tributárias

Dois respondentes mencionaram no quesito "outros", como fonte de alta complexidade, a interpretação das normas tributárias. De fato, considerando o grande quantitativo de normas tributárias, incluídas leis, decretos, medidas provisórias, portarias, resoluções, instruções normativas, convênios, pareceres, entre outras, e o modo como o texto legal é formulado e redigido, torna-se difícil uma compreensão precisa por parte do contribuinte.

No que se refere aos fatores que mais contribuem para o aumento dos custos de conformidade, considerando uma escala de 1 a 10 (sendo que o valor 1 corresponde ao fator que mais gera custos de conformidade e 10 o contrário). A complexidade da legislação tributária foi considerada o principal fator gerador de custos de conformidade, corroborando a questão anterior de que a dificuldade de interpretação das normas é fonte de custos. Em seguida, ficou a alternativa sobre as alterações das normas tributárias.

Percebe-se que os resultados corroboram o estudo de Green (1994 apud Evans, 2003), realizado no Reino Unido, onde se constatou que havia um aumento dos custos 
de conformidade associado diretamente ao sistema tributário, e as causas identificadas dessa tendência foram a complexidade do sistema tributário e as deficiências no processo legislativo.

Hall (1994) reforça que, juntamente com a rotina de tarefas de conservação de arquivos, preparação de relatórios financeiros, preenchimento de formulários fiscais e atendimento a auditorias fiscais, o alto custo de conformidade tributária resulta dos esforços dos contribuintes para compreender, e adaptar-se às complexas e frequentemente modificadas questões fiscais.

Outro aspecto analisado diz respeito às ações da empresa frente à instabilidade das normas tributárias, evidenciando como esta lida com as frequentes alterações na legislação: treinamento de pessoal interno, leitura da legislação fiscal e dos manuais e contratação de consultoria externa. A tabela 2 apresenta as ações mais utilizadas pela empresa, na percepção dos pesquisados, que poderiam indicar até 03 opções.

Tabela 2 - Ações da empresa para lidar com as alterações da legislação tributária

\begin{tabular}{l|c}
\hline \hline \multicolumn{1}{c|c}{ Aspectos } & Freqüência \\
\hline Treinamento de pessoal interno & 7 \\
Leitura da legislação fiscal e dos manuais & 5 \\
Contratação de consultoria externa & 4 \\
Participação em seminários, congressos, simpósios & 3 \\
Troca de informações entre a equipe de trabalho & 3 \\
Acesso a plantões fiscais & 2 \\
\hline \hline
\end{tabular}

Fonte: Dados da pesquisa

Os custos de conformidade podem ser gerados dentro da empresa ou pelas atividades relacionadas à tributação realizadas por profissionais externos. A pesquisa revelou que os principais custos de conformidade internos, na visão dos respondentes, são identificados na Controladoria, onde foi considerado um alto grau de participação no estudo, discussão e cumprimento da legislação tributária, em seguida, ficaram os setores Financeiro, Jurídico e Gestão de pessoas.

Entre outras atribuições relacionadas ao cumprimento das disposições tributárias, a gerência de Controladoria da Cagece realiza o planejamento, cálculo dos tributos e controle de obrigações acessórias; a gerência financeira efetua e presta 
informações sobre pagamento e retenções na fonte de tributos (INSS, PIS, COFINS, CSLL, IR) dos serviços prestados por terceiros; a gerência de Pessoas calcula e controla os tributos incidentes sobre a folha de pagamento (INSS, Salário-educação, SAT, INCRA, SENAI, SESI, SEBRAE, FGTS) e a retenção de tributos na fonte de seus empregados. Por sua vez, a Procuradoria Jurídica assessora todas as unidades organizacionais da empresa se pronunciando sempre que solicitada a respeito dos assuntos tributários em pauta ou remetendo questões de maior complexidade para escritório de advocacia especializado.

Nos custos externos, o predomínio é dos custos com advogados, auditoria, informática e treinamentos. A empresa mantém contrato com escritório de advocacia empresarial especializado na prestação de serviços de acompanhamento de questões tributárias, para orientações preventivas até defesas nas esferas administrativas e judiciais, e com empresa de consultoria e auditoria externa. A companhia adquire de uma empresa responsável por desenvolvimento de softwares o sistema ERP que atende às áreas contábil-fiscal e financeira, entre outras.

Os principais custos externos identificados pelos respondentes (custos com auditores, consultores e advogados) podem ser considerados, segundo a classificação apresentada por Das-Gupta (2003), Warburton e Hendy (2006) e Evans et al (2000), como custos de conformidade voluntários, pois estão, principalmente, associados ao planejamento tributário, à tentativa de reduzir as obrigações fiscais e apelações fiscais. A participação dos setores de Controladoria e Financeiro na geração de custos de conformidade internos está normalmente relacionada ao custo do cumprimento da legislação tributária (custos obrigatórios), como manutenção de livros fiscais, preenchimento de formulários, obtenção de registros e permissões requeridas pela legislação, entre outras atividades exigidas pela lei.

As atividades relacionadas à tributação em que a empresa emprega maiores esforços de tempo e recursos, na opinião dos respondentes foram por ordem de prioridade: as atividades referentes ao cálculo e recolhimento dos tributos incidentes sobre a atividade da empresa e as ações com treinamento de pessoal interno para a realização de tarefas relacionadas a impostos, corroborando o resultado obtido na 
tabela 2, de que a empresa investe em treinamento para lidar com a instabilidade tributária.

Observa-se que as atividades relacionadas à tributação (calcular e recolher tributos incidentes sobre a atividade da empresa; efetuar as retenções e recolhimentos de tributos retidos na fonte) e à prestação de informações à administração tributária, através do preenchimento e entrega de declarações, são as que Slemrod e Blumenthal (1993) classificam como filing activites, onde os custos de conformidade decorrem das próprias atividades de coleta de dados, preparação de declarações fiscais e cálculo dos tributos.

A atividade de treinamento de pessoal interno para a realização de tarefas relativas a impostos, apontada por 06 respondentes, pode ser considerada, conforme a classificação de Slemrod e Blumenthal (1993), como pre-filing activite, cujos custos de conformidade surgem do planejamento tributário, obtenção de orientação tributária e informações, e manutenção de arquivos relacionados à matéria fiscal. A contratação de consultoria especializada, também pode ser classificada como atividade geradora de pre-filing costs.

Foram também feitos questionamentos acerca da qualidade da regulamentação tributária, a relevância dos custos de conformidade e as estratégias da empresa para conviver com a complexidade tributária. Os respondentes deveriam indicar o grau de concordância ou discordância com as afirmações propostas.

Conforme os resultados obtidos, os supervisores e colaboradores das áreas pesquisadas na empresa concordam que o ônus tributário imposto aos contribuintes tem aumentado e, a complexidade das normas torna o seu cumprimento mais difícil, mais custoso e sua dinâmica leva as empresas a recorrerem a serviços de profissionais especializados.

Dentre os pesquisados, sete concordam, no todo ou em parte, que, além dos tributos incidentes, os contribuintes estão obrigados a um excessivo número de obrigações acessórias e isto tem interferido na competitividade das empresas.

Para cinco respondentes, o tempo e o esforço empregados em atividades como preenchimento de declarações, retenção de tributos, manutenção de arquivos, 
consomem importantes recursos da empresa e geram pouco ou nenhum benefício para os negócios. Apenas dois dos pesquisados discordaram parcialmente dessa afirmativa. O resultado encontra correspondência em Evans et al. (2000), que identificam benefícios gerenciais na conformidade tributária, ao afirmar que a necessidade de se ter uma rigorosa manutenção de arquivos a fim de obedecer às exigências das leis fiscais pode proporcionar uma base melhor para a tomada de decisões na empresa.

No que se refere à percepção de que os custos de conformidade representam um ônus para a empresa, seis respondentes concordaram, parcialmente, que, embora haja essa percepção para a empresa, a mesma não possui controle em relação a esses custos. O resultado fortifica a afirmação de Bertolucci (2003) de que as organizações não estão preparadas para levantar somente a parte dos custos das várias áreas da empresa que têm recursos voltados ao atendimento de normas tributárias e que mesmo nos países mais desenvolvidos não é prática comum criar mecanismos ou dispositivos para apurar ou controlar os custos de conformidade.

Todos os respondentes estão de acordo que se faz necessária uma maior atenção aos custos de conformidade à tributação nas políticas tributárias adotadas no Brasil. Tendo em vista a quantidade de obrigações acessórias previstas nas legislações federal, estaduais e municipais, o tema merece espaço e discussão das autoridades governamentais, no sentido de adotar medidas capazes de reduzir os custos de conformidade dos setores mais afetados e evitar a simples transferência de custos administrativos aos contribuintes.

Tendo por objetivo, considerar outras fontes de evidência, complementando os resultados obtidos com o questionário, foram feitas entrevistas semi-estruturadas, desenvolvidas a partir de um roteiro construído com perguntas abertas.

Foram realizadas 06 entrevistas nos níveis de assessoria e gerência da companhia, tendo como entrevistados 02 assessores técnicos da Presidência, 0 assessor da Procuradoria Jurídica, o gerente de Controladoria, o gerente Financeiro e o gerente de Pessoas. O gerente da área de estudos e estratégias econômicofinanceira optou por não participar da pesquisa.

Ao serem informados sobre o tema da pesquisa, todos os entrevistados se 
mostraram interessados, ressaltando a originalidade do estudo. Embora todos reconhecessem a existência de custos de conformidade na empresa e a importância de se conhecer as determinantes e as consequências desses custos, afirmaram que ainda não se tratava de um assunto discutido dentre as questões tributárias da companhia.

Quando questionados sobre as estratégias da companhia para enfrentar ou conviver com a crescente complexidade tributária, dada a limitação de orçamento da empresa, os entrevistados enfatizaram a constante capacitação dos colaboradores da companhia, através de treinamentos. Os assessores técnicos frisaram que, embora os gastos com treinamento se caracterizem como custos de conformidade, a capacitação pode gerar benefícios no sentido de despertar uma postura pró-ativa dos colaboradores para o planejamento tributário; afirmando ainda que, a participação dos funcionários em eventos relacionados à área tributária provoca troca de experiências e insigths para ações que visem minimizar a carga incidente.

O gerente financeiro ressaltou que, além dos recursos aplicados em cursos e treinamentos, há também que se considerar o impacto gerado pela ausência do funcionário em treinamento, dado o reduzido quadro de pessoal nessa área da companhia. Destacou, também, a dificuldade para lidar com as leis orgânicas dos diversos municípios onde há prestação de serviços, para efeito da retenção do ISS. Ele mencionou um plano de ação da empresa que visa operacionalizar as retenções nas próprias unidades do interior do Estado, o que certamente demandará recursos em treinamento, contratação de pessoal e sistemas, mas facilitará o cumprimento das obrigações com o Fisco municipal, tendo em vista que grande parte do serviço está atualmente centralizada na sede administrativa.

No que se refere às estratégias da companhia para enfrentar a crescente complexidade tributária, os entrevistados informaram que a empresa dispõe de consultoria e assessoria de um escritório especializado nas questões tributárias, de modo a promover planejamento tributário, por meio de alternativas legais para redução do ônus fiscal, até demandas nas esferas administrativas e judiciais. Sobre os custos de conformidade associados ao planejamento tributário, Evans et al. (2000) destacam 
que as ações de elisão fiscal são empreendidas pelos contribuintes tendo em vista que seus custos são presumivelmente menores que as consequentes reduções nas suas obrigações tributárias.

Os entrevistados mencionaram também como estratégias para conviver com a complexidade a assinatura de revistas especializadas na área fiscal, consulta a plantões fiscais e a melhoria do controle informatizado, que minimiza eventuais falhas humanas.

Quando indagados sobre a existência de algum procedimento que reduziria o total da obrigação tributária, mas que a empresa deixou de fazer por causa da complexidade, os assessores entrevistados afirmaram que a empresa sempre busca alternativas legais para minimizar a carga tributária independente do grau de dificuldade para obtenção do benefício.

O gerente de Controladoria destacou que a empresa evita as operações que possam gerar riscos de contingência fiscal e que procura sempre, em parceria com empresas de consultoria contratadas, ver novas formas legais de redução da carga tributária.

Ao supor a possibilidade da legislação tributária não mudar mais, os entrevistados citaram os seguintes pontos em que poderia haver redução de gastos na empresa:

- A atualização de softwares se tornaria desnecessária ou menos frequente e os gastos diminuiriam, tendo em vista que o suporte em decorrência de alterações na legislação fiscal não está incluso no contrato inicial;

- Redução dos gastos com treinamentos direcionados tão-somente a tratar das alterações na legislação e mudanças nos formulários e declarações prestadas pela empresa;

- Redução do tempo dedicado à leitura de novos manuais e adaptação a novas regras pelos funcionários;

- Redução no contrato de assessoria e consultoria tributária.

O gerente financeiro ressaltou que a estabilidade das normas tributárias 
permitiria também uma maior segurança quanto ao planejamento financeiro e orçamentário elaborado pela empresa.

Quando questionado se a empresa está satisfeita com sua interação com o Fisco (federal, estadual e municipal), o gerente de Controladoria destacou as exigências para a obtenção do alvará de funcionamento das Prefeituras e a dificuldade dos órgãos federais em emitirem Certidões Negativas de Débitos (CND), especialmente, se há débitos questionados judicialmente, situação esta também mencionada pela assessora jurídica.

Essa queixa se coaduna com o levantamento da Pricewaterhouse Coopers (2006), realizado com 117 grupos empresariais brasileiros, que constatou que 92,7\% dos empresários já retardaram ou perderam negócios devido à dificuldade de conseguir a tempo a Certidão

Negativa de Débito (CND), documentação exigida de quem quer participar de licitação, obter financiamento ou empréstimo bancário.

O gerente de Pessoas fez menção aos custos de conformidade gerados pelas fiscalizações, com os gastos de tempo e recursos no atendimento aos fiscais, na preparação de relatórios, expedição de cópias, e, porventura, dispêndios com advogados para apelações fiscais.

Foram solicitadas dos entrevistados, sugestões para simplificação do sistema tributário e/ou para a redução dos custos de conformidade à tributação. Os assessores da Presidência destacaram que o ponto fundamental seria uma maior participação do setor de saneamento no processo legislativo, através do monitoramento, discussão e apresentação de propostas para o aperfeiçoamento da legislação tributária aplicável ao setor. Enfatizaram que, dada a relevância do setor para o país, especialmente no que se refere ao caráter social de suas atividades, esse assunto deveria ser pauta nas políticas tributárias para o setor, de maneira que as empresas de saneamento pudessem concentrar seus esforços e recursos no alcance das metas de universalização dos serviços de água e esgoto. Sugeriram ainda a existência de incentivos fiscais que permitissem a aplicação integral dos tributos pagos diretamente nas atividades sociais desempenhadas pela companhia. 
O assessor da Procuradoria Jurídica expôs que a existência de regras mais claras e formulários mais simples facilitariam a vida dos contribuintes. A redução do número de tributos e da quantidade de obrigações acessórias foi a sugestão dada pelo gerente de Pessoas para a simplificação do sistema tributário e redução dos custos de conformidade à tributação.

O gerente de Controladoria defendeu a criação de um imposto único para cada ente federativo (União, Estados e Municípios). A proposta do imposto único é sustentada por Cintra (2006) que estima que "a economia de custos da máquina arrecadadora do poder público e dos custos de pessoal administrativo do setor privado poderá chegar a $20 \%$ da arrecadação tributária bruta, acarretando uma participação de $4,4 \%$ do PIB". Cintra (2006) ressalta que esses recursos poderiam ser canalizados para investimentos produtivos e alavancar o crescimento econômico.

Em síntese, os resultados obtidos revelam que os gestores e colaboradores da empresa pesquisada reconhecem a existência dos custos de conformidade à tributação e seu crescimento nos últimos anos, principalmente em decorrência da complexidade e instabilidade das regulamentações fiscais. Há a percepção de que os principais custos internos são os da Controladoria e Financeiro e decorrem do cumprimento de obrigações previstas na legislação fiscal. Os custos de conformidade externos estão relacionados principalmente ao planejamento tributário e apelações fiscais.

\section{CONSIDERAÇÕES FINAIS}

Os gestores e colaboradores da Companhia de Água e Esgoto do Ceará (Cagece), reconhecem a existência de custos de conformidade na empresa e a importância de se conhecer os determinantes e as consequências desses custos, mas esse não é um assunto discutido dentre as questões tributárias da companhia, posto que as suas ações e preocupações, no âmbito fiscal, estão voltadas para a redução dos tributos (impostos, taxas, contribuições) pagos.

A percepção dos gestores e colaboradores a respeito dos custos de conformidade é instintiva, de acordo com as experiências e vivências de cada 
respondente, tendo em vista que a companhia não monitora seus custos de conformidade em seu sistema de informações.

Assim, conclui-se que há uma percepção intuitiva da existência dos custos de conformidade à tributação na empresa pesquisada, pois não há informações sobre os itens que compõem esses custos, nem mecanismos e dispositivos para apurá-los ou controlá-los. Os pesquisados reconhecem a importância do assunto e entendem que essa matéria deva figurar na agenda política do País, visando o aperfeiçoamento da legislação tributária brasileira e minimização do ônus imposto ao contribuinte.

\section{REFERÊNCIAS}

ARRETCHE, M.T.S. Política Nacional de Saneamento: 1999. A Reestruturação das Companhias Estaduais.

BRASIL. 2004. Constituição Federal (1988). 22ª ed. São Paulo: Atlas. 2003. Código Tributário Nacional. $32^{a}$ ed. São Paulo: Saraiva.

1990. Lei $\mathbf{n} . \mathbf{0}$ 11.445, de 05 de janeiro de 2007. Estabelece diretrizes nacionais para o saneamento básico; altera as Leis nos 6.766, de 19 de dezembro de 1979, 8.036, de 11 de maio de 1990, 8.666, de 21 de junho de 1993, 8.987, de 13 de fevereiro de 1995; revoga a Lei no 6.528, de 11 de maio de 1978; e dá outras providências. Disponível em <http://www.planalto.gov.br/ccivil_03/_Ato20072010/2007/Lei/L11445.htm>, acesso em:8/04/2007.

.2003. Mensagem de veto $n .-362$, de 31 de julho de 2003. Disponível em: <http://www.planalto.gov.br/ccivil_03/Leis/Mensagem_Veto/2003/Mv362-03.htm>, acesso em: 17/04/2007.

CINTRA, M. 2005. Burocracia e opressão. Tributario. net, São Paulo, disponível em http://www.tributario.net/artigos/artigos_ler.asp?id=33002, acesso em: 8/06/2006.

Companhia de Água e Esgoto do Ceará. [Institucional]. Disponível em www.cagece.com.br, acesso em: 6/08/2006.

DAS-GUPTA, A. 2003. The Income Tax Compliance Cost of Corporations in India, 2000-01. Goa Institute of Management. Disponível em <http://www.nipfp.org.in/working\%20paper/wp08.pdf>, acesso em:18/02/2007.

EVANS, C. 2003. Studying the studies: an overview of recent research into taxation 
Custos de Conformidade à Tributação: Uma análise da percepção de gestores e colaboradores emuma

Glavany Lima Maia, Maria Naiula Monteiro Pessoa, Sandra Maria dos Santos, Augusto César Cabral

operating costs.

Journal of Tax Research, 1(1):64-92, disponível em <http://bar.austlii.edu.au/au/journals/eJTR/2003/4.html>, acesso em: 6/08/2006.

. et al. 2000. Tax compliance costs: research methodology and empirical evidence from Australia.

53(2):229-252,

National

Tax Journal, $<$ http://ntj.tax.org/wwtax/ntjrec.nsf/08044A4AEB96D54B85256AFC007F2302/\$FILE/v53 n2229.pdf >. Acesso em: 18/02/2007.

TRAN-NAM, B. 2001. The compliance and administrative costs of the TVM: What are the implications? In: Australian Tax Research Foundation. ATAX and the Board of Taxation Tax Value Method Consultative Conference. Disponível em

$<$ http://www.taxboard.gov.au/content/Tax_Value_Method/tvm_papers/downloads/evans. pdf>, acesso em: 20/02/2007.

HALL, A.P. 1994. The Cost of Unstable Tax Laws. Tax Foundation. Special Report.

http://www.taxfoundation.org/files/79985a8649fa8a5d501dec544dc13960.pdf, acesso em: 18/02/2007.

AMARAL, G.L. e OLENIKE, J.E. 2005. Instituto Brasileiro De Planejamento Tributário - $\quad$ IBPT. Disponível em http://www.ibpt.com.br/estudos/estudos.viw.php?estudo_id=a5771bce93e200c36f7cd9dfd0e 5deaa, acesso em: 16/10/2006.

\section{AMARAL, G.L.; et al. 1988. Quantidade de normas editadas no Brasil: 18 anos de Constituição $\quad$ Federal de $1988 \quad$ IBPT. \\ Disponível em \\ http://www.ibpt.com.br/estudos/estudos.viw.php?estudo_id=9a1158154dfa42caddbd06 \\ 94a4e9bdc8, acesso em:16/10/2006}

AMARAL, G.L. e OLENIKE, J.E. 2006. Carga tributária Brasileira (revisada). IBPT. Disponível em http://www.ibpt.com.br/arquivos/estudos/2006__C_T_B_(REVISADA).pdf, acesso em: 21/02/2007.

MACHADO, H.B. 2005. Curso de Direito Tributário. 26 a ed. São Paulo, Malheiros, OLIVEIRA, L.M.; et AL. 2003. Manual de Contabilidade Tributária. 2 a ed. São Paulo: Atlas,

POPE, J. 2000. The administrative and compliance costs of international taxation: an introduction for research students. Curtin university, Austrália. Outubro 2000. Disponível em 
$<$ http://www.cbs.curtin.edu.au/files/cbsstaffpublications/The_administration_and_compli ance_costs_of_international_taxation.doc>, acesso em: 21/02/2007

Price Waterhouse Coopers. Estudo mostra que quase todas as empresas já perderam negócios por causa de certidões negativas. Disponível em http://cbn.globoradio.globo.com/cbn/arquivos/economia/2006/07/1/economia20060716.asp, acesso em:6/04/2007.

REZENDE, C. Pandemônio Tributário. Disponível em <http://www.econ.pucrio.br/gfranco/PANDEMONIO_TRIBUTARIO.htm>, acesso em: 18/02/2007.

SANDFORD, C. 1995. Tax Compliance Costs Measurement and Policy. Bath, UK: Fiscal Publications.

;GODWIN, M. e HARDWICK, P. 1989. Administrative and Compliance Costs of Taxation. Bath, UK: Fiscal Publications.

SLEMROD, J. 2006. The (compliance) cost of taxing business. University of Michigan. Disponível em

<http://www.competitivetaxation.org/papers/Slemrod-businesscompliancecosts.pdf>, acessoem:

21/02/2007.

BLUMENTHAL, M. 1993. The Income Tax Compliance Cost of Big Business. Tax Foundation, Washington. Disponível em

<http://www.taxfoundation.org/files/a3a792509ccb161d00a8895e31cb90ba.pdf>, acesso

em:

18/02/2007.

;VENKATESH, V. 2002. The Income Tax Compliance Cost of Large and Mid-Size Businesses. Office of Tax Policy Research. Disponível em <http://www.bus.umich.edu/OTPR/WP2004- 4.pdf>. Acesso em: 18/02/2007.

WARBURTON, R. e HENDY, P. 2006. International comparisation of Australia's Taxes. Disponível em

$<$ http://comparativetaxation.treasury.gov.au/content/report/downloads/15_Chapter_13.p df>, acesso em: 21/02/2007.

YIN, R.K. 2005. Estudo de Caso: planejamento e métodos. $3^{\text {a }}$ ed. Porto Alegre: Bookman, 212p.

Data de Submissão: 20/11/2008

Data de Aceite: 16/12/2008 